\title{
Analisis Sistem Informasi Berbasis Cobit 5 (Studi Kasus: LTC UKSW)
}

\author{
Novian Steven Farera Messakh *1 ${ }^{1}$, Dr. Andeka Rocky Tanaamah, S.E., M.Cs. ${ }^{2}$ \\ ${ }^{1,2}$ Universitas Kristen Satya Wacana; Jl. Diponegoro No.52-60, Salatiga, \\ Kec. Sidorejo, Kota Salatiga, Jawa Tengah 50711, (0298) 321212 \\ ${ }^{3}$ Jurusan Sistem Informasi, FTI UKSW, Salatiga \\ e-mail:*11682016072@ student.uksw.edu, ${ }^{2}$ atanaamah@uksw.edu
}

\begin{abstract}
Abstrak
Penerapan TI di suatu perusahaan merupakan kerangka kerja yang dapat meningkatkan keuntungan organisasi. TI harus dikelola dengan baik untuk menghasilkan manfaat yang ditargetkan. LTC merupakan organisasi yang menggunakan Cobit 5 sebagai alat untuk mengelola tujuan bisnis terkait tata kelola TI yang ada. Tata kelola membutuhkan analisis untuk mengevaluasi, menilai kematangan dan membuat rekomendasi. LTC belum mengevaluasi tata kelola TI yang ada, sehingga LTC tidak memiliki kerangka kerja untuk dapat mengetahui kondisi, manfaat dan dampak dari penerapan TI yang sudah dijalankan. Cobit 5 merupakan kerangka kerja keseluruhan yang komprehensif, karena itu dapat disesuaikan dengan tata kelola yang ada di LTC. Domain pada Cobit 5 yang difokuskan penulis adalah "Delivery, Service and Support (DSS)". Domain tersebut berfokus dengan evaluasi layanan TI dan mendukung berjalannya proses bisnis organisasi, serta pengendalian jangka panjang proses bisnis, evaluasi, dan proses perencanaan. Hasilnya menunjukan bahwa proses yang diukur yaitu pada DSS 1, DSS 2, DSS 3, DSS 4 dan DSS 5, DSS 6 berada pada level 1 (Performed Process) menunjukkan bahwa proses telah dijalankan pada level ini dan tujuan proses telah tercapai. Setiap proses subdomain diberikan rekomendasi perbaikan yang nantinya bisa mempengaruhi tingkat kematangan saat ini untuk menuju tingkat perbaikan dan sampai pada kematangan yang ingin dicapai.
\end{abstract}

Kata kunci - tata kelola TI, cobit 5, domain dss, tingkat kematangan

\begin{abstract}
The application of IT in a company is a framework that can increase organizational profits. IT must be properly managed to generate targeted benefits. LTC is an organization that uses Cobit 5 as a tool to manage business objectives related to existing IT governance. Governance requires analysis to evaluate, assess maturity and make recommendations. LTC has not evaluated existing IT governance, so LTC does not have a framework to be able to find out the conditions, benefits and impacts of implementing IT that has been implemented. Cobit 5 is a comprehensive overall framework, because it can be adapted to existing governance in LTC. The domain on Cobit 5 the author is focused on is "Delivery, Service and Support (DSS)". This domain focuses on evaluating IT services and supporting the organization's business processes, as well as long-term control of business processes, evaluation, and planning processes. The results show that the measured processes are in DSS 1, DSS 2, DSS 3, DSS 4 and DSS 5. , DSS 6 is at level 1 (Performed Process) indicating that the process has been executed at this level and the process objectives have been achieved. Each sub-domain process is given recommendations for improvement which can later affect the current maturity level towards the level of improvement and arrive at the maturity to be achieved.
\end{abstract}

Keywords - IT Governance, Cobit 5, DSS Domain, Maturity Level 


\section{PENDAHULUAN}

Diakui bahwa TI memiliki peran penting dalam meningkatkan praktik tata kelola perusahaan, karena pada proses bisnis yang kritis biasanya akan secara otomatis dan bergantung pada informasi yang diberikan oleh sistem TI untuk pengambilan keputusan mereka. Strategi yang disusun harus selaras dengan visi - misi perusahaan, sehingga keberadaan TI mampu mendukung pencapaian tujuan perusahaan secara langsung maupun melalui dukungan terhadap aktivitas operasional. Oleh karena itu, agar implementasi TI dapat berjalan dan dapat digunakan secara maksimal, organisasi memerlukan Tata Kelola TI. Menurut Grembergen (2004), "Tata kelola TI adalah proses dimana direktur, manager dan pihak lain yang bertanggung jawab atas tata kelola perusahaan dapat memastikan bahwa system dan aplikasi TI sudah mencapai tujuan perusahaan dan pada saat yang sama risiko TI dapat dikelola dengan tepat" [1]. Language Training Center (LTC), yang sebelumnya dikenal sebagai. Language Training Center (LTC) memiliki sistem informasi administrasi yang diharapkan dapat menjadi salah satu cara yang dapat menunjang peningkatan tujuan dan sasaran bisnis organsasi. LTC belum mengetahui sejauh mana pemanfaat teknologi informasi yang ada serta dampak yang diperoleh dalam pelaksanaannya terhadap progres pencapaian tujuan bisnis yang terkait dengan tata kelola pengelolaan sistem informasi yang menjadi kelemahan dan apa saja rekomendasi yang dapat dihasilkan.

Fokus pada penelitian kali ini adalah impelementasi framework COBIT 5 pada domain DSS. Domain tersebut dipilih karena sesuai dengan kondisi TI yang ada di LTC yang diimplementasikan pada teknologi informasi saat ini, yang telah direncanakan (plan), telah dibangun (build), dan saat ini dijalankan (run) dan karena teknologi informasi berpatokan dengan workflow dan proses bisnis yang ada. Tujuan dari penelitian ini adalah menganalisis dan merancang tata kelola TI menggunakan framework COBIT 5 pada domain DSS berdasarkan domain proses prioritas kebutuhan di lingkungan LTC dan merekomendasikan struktur organisasi untuk meningkatkan value business dan value IT bagi LTC. Sedangkan manfaat dari penelitian diharapkan dapat membantu LTC dalam mengetahui kondisi tata kelola TI saat ini dan mengimplementasikan rekomendasi struktur organisasi sasaran, prosedur proses dan dokumen

\section{METODE PENELITIAN}

\subsection{Penelitian Terdahulu}

Cobit 5 menjadi suatu kerangka kerja pengelolaan TI paling signifikan dan yang paling cocok untuk melakukan audit karena memberikan panduan komprehensif seputar proses kerja TI dan tujuan bisnis yang ada. Cobit 5 juga berkontribusi pada penerapan prinsip-prinsip utama tata kelola perusahaan yang baik, khususnya, di sektor publik. Hal ini menunjukkan bahwa ada banyak tautan, yang secara eksplisit dan implisit diekspresikan melalui seperangkat instrumen tata kelola TI, yang mencocokkan prinsip tata kelola yang baik dengan tujuan perilaku implementasi kerangka kerja tata kelola TI. Cobit 5 dapat mengevaluasi potensi dan tujuan pengendalian paling penting dalam pemilihan keputusan audit dalam organisasi yang diharapkan dapat bertahan lama dan relevan. Pendapat ini diangkat dari penelitian Omari, L. A., Barnes, P., \& Pitman, G. (2012) tentang Optimising COBIT 5 for IT Governance: Examples from the Public Sector [2] dan penelitian yang dilakukan oleh Carlos, J., Carlos, G., \& Isaac, L. (2014) mengenai Implementing Good Governance Principles for The Public Sector in Information Technology Governance Frameworks[3].

Evaluasi kinerja terhadap penerapan tata kelola SI/TI dengan kerangka kerja Cobit 5 dapat dimanfaatkan sebagai suatu reference model untuk memastikan kualitas penerapan tata 
kelola TI dan bertujuan untuk menghadapi permasalahan tentang seberapa optimal kinerja sumber daya manusia yang ada. Ide ini merupakan penelitian yang dilakukan oleh Manuputty A (2016) tentang Evaluasi Kinerja Sistem Informasi Starclick [4] dan penelitian oleh Sitokdana M (2018) yang membahas tentang Evaluasi Tata Kelola TI Dinas Pariwisata \& kebudayaan [5].

Dalam pelaksanaannya Cobit 5 juga mempunyai standar yang dapat digunakan untuk mengevaluasi tata Kelola TI yang ada dalam organisasi, tingkat kapabilitas pada organisasi sangat penting karena dapat dijadikan acuan untuk mengukur implementasi TI dan dapat digunakan untuk mengetahui kendala tata Kelola TI yang belum matang. Pendapat ini diangkat dari penelitian Wijaya A.F (2017) tentang Evaluasi kinerja Sistem informasi E-Filling [6], penelitian yang dilakukan oleh Ambarwati A (2016) mengenai Implementasi Teknologi Informasi [7] dan penelitian dari Kristanto T (2016) tentang Analisis Tingkat Kematangan EGovernment [8].

\section{2 Landasan Teori}

\section{2.1 Tata Kelola}

Tata kelola TI merupakan tanggung jawab organisasi, kepala direksi, manajemen eksekutif, dan departemen manajemen teknologi informasi yang bertugas sebagai pengontrol perumusan dan implementasi strategi SI / TI untuk memastikan bahwa sumber daya SI / TI konsisten dengan bisnis organisasi. Grembergen menekankan konsep tata kelola TI dalam bagaimana organisasi melihat, mengelola dan mengoptimalkan sumber daya SI / TI mereka untuk mendukung tujuan organisasi.[1]

\section{2.2 Auditing}

Menurut Arens dan Loebbecke ( 2003 ), auditing adalah "pengumpulan dan evaluasi bukti tentang informasi untuk menentukan dan melaporkan derajat kesesuaian antara informasi itu dan kriteria yang ditetapkan". Auditing harus dilakukan oleh pihak yang kompeten dan independen. Dari definisi ini mencakup beberapa kata atau frase kunci yaitu informasi dan kriteria yang telah ditetapkan, mengumpulkan dan mengevaluasi bukti, dan orang yang kompeten dan independen.[9]

\section{2.3 Cobit 5}

Menurut ICASA (2012) COBIT adalah proses bisnis yang digunakan untuk tata kelola dan manajemen TI perusahaan. Versi ini menggabungkan ide-ide terbaru dalam tata kelola organisasi dan teknologi manajemen, dan menyediakan prinsip, praktik, alat analisis, dan model yang diakui secara global untuk membantu meningkatkan kredibilitas dan nilai sistem informasi [10].

\section{2.4 Domain DSS}

Domain Deliver, Service dan Support (DSS) berfokus dengan proses layanan TI dan dukungan teknis, mencakup keamanan sistem, kontinuitas layanan, pelatihan, dan manajemen data berkelanjutan. Domain DSS berisi beberapa tujuan pengendalian, yaitu DSS 1 (Mengelola Operasi), DSS 2 (Mengelola Permintaan Layanan dan Insiden), DSS 3 (Mengelola Masalah), DSS 4 (Mengelola Keberlanjutan), DSS 5 (Mengelola Keamanan Layanan), DSS 6 (Mengelola Kontrol Proses Bisnis).

\section{2.5 RACI Chart}

RACI merupakan bentuk pemetaan antara sumber daya dan aktivitas di setiap proses organisasi. Model RACI merupakan matriks dari semua kegiatan atau otorisasi pengambilan 
keputusan dan harus dilaksanakan dalam suatu organisasi yang terkait dengan semua pihak atau posisi (ICASA, 2012).[10]

\section{2.5 Process Assesment Model}

COBIT 5 PAM memberikan dasar bagi organisasi untuk mengevaluasi proses teknologi informasi COBIT, dan dapat mengevaluasi kemampuan proses untuk mendukung peningkatan. Evaluasi didasarkan pada bukti untuk memastikan bahwa proses evaluasi dapat diandalkan dan konsisten, serta dapat dilakukan secara berkala di bidang tata kelola dan manajemen TI.

\subsection{Metodologi Penelitian}

Dalam penelitian ini metode yang digunakan untuk mengumpulkan data adalah metode kualitatif berfungsi mengumpulkan data melalui observasi dan wawancara, sedangkan metode kuantitatif untuk mengumpulkan data melalui survei kuesioner. Beberapa narasumber yang dilibatkan seperti Ibu Johanna M. Alfons - Likumahuwa sebagai direktur, Bapak Suyoto sebagai staf IT, dan Ibu Anisia Budi Prabawani sebagai staf administrasi. Penulis juga melakukan wawancara untuk pengumpulan data yang diperlukan, seperti profil organisasi LTC dan tujuan bisnis yang ada. Pengumpulan data dilakukan di LTC UKSW dari 13 Januari hingga 31 Maret 2020.

Tahap akhir dari penelitian adalah menarik kesimpulan dari hasil penelitian, dan menarik kesimpulan dari hasil analisis dan pengolahan data secara lengkap juga memberikan rekomendasi untuk perbaikan tata kelola TI LTC UKSW. Gambar 1 di bawah ini merupakan alur tahap penelitian dari awal penelitian hingga akhir penelitian.

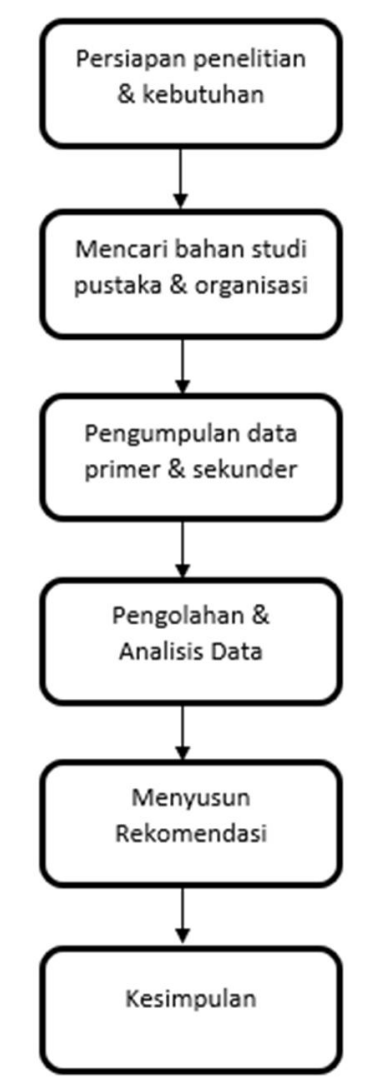

Gambar 1. Tahap Penelitian 


\section{HASIL DAN PEMBAHASAN}

\subsection{Pemetaan Cobit 5}

Pada tahap ini, penyesuaian dilakukan antara sasaran bisnis LTC dan sasaran teknologi informasi. Penulis menggunakan alat IT Balanced Scorecard (IT BSC) untuk menangani proses penyesuaian, yang digunakan untuk memetakan proses bisnis internal organisasi dari perspektif keuangan, pelanggan, proses bisnis internal, pembelajaran dan pengembangan. Tahap ini dilakukan agar organisasi dapat menggunakan dukungan TI yang telah tersedia untuk mencapai tujuannya agar dapat melangkah ke tahap selanjutnya.

\subsubsection{Identifikasi RACI}

Narasumber yang terlibat dibagi kedalam 4 bagian peran yang terdapat pada tabel RACI (Responsible, Accountable, Consulted, and Informed) pada tabel 1 dibawah ini.

Tabel 1. Identifikasi RACI

\begin{tabular}{|l|l|}
\hline Peran RACI (Role) & \multicolumn{1}{|c|}{ Jabatan } \\
\hline Responsible & Direktur, Staf IT \\
\hline Accountable & Direktur, Staf IT \\
\hline Consulted & Direktur, Staf IT, Staf Administrasi \\
\hline Informed & Direktur, Staf IT, Staf Administrasi \\
\hline
\end{tabular}

\subsubsection{Analisis Risiko}

Untuk mengukur kinerja eksekutif di masa depan diperlukan ukuran komprehensif yang meliputi empat perspektif, yaitu perspektif keuangan, perspektif pelanggan, perspektif bisnis internal, serta perspektif pertumbuhan dan pembelajaran, yang disebut dengan Balance Scorecard. Balance Scorecard digunakan untuk menyeimbangkan usaha dan perhatian eksekutif ke kinerja keuangan dan nonkeuangan, serta kinerja jangka pendek dan kinerja jangka panjang (Kaplan dan Norton, 1990). [11] Dari data tersebut akan diolah kedalam beberapa perspektif yang ada pada Balanced Scorecard, hasil dari proses analisis menggunakan metode ini akan mendapatkan hasil yang dapat digunakan sebagai proses pemetaan tujuan strategis LTC.

Tabel 2. Identifikasi Balanced Scorecard

\begin{tabular}{|c|c|}
\hline Perspektif & Tujuan Strategis \\
\hline Finansial & $\begin{array}{l}\text { Mengontrol penggunaan dana dalam } \\
\text { keberlangsungan organisasi }\end{array}$ \\
\hline Pelanggan & $\begin{array}{l}\text { Memberikan pengajaran y ang optimal } \\
\text { dalam pembelajaran bahasa dan budaya } \\
\text { agar mendapat ilmu yang dapat } \\
\text { digunakan untuk sekolah,bekerja di } \\
\text { kalangan nasional maupun internasional. }\end{array}$ \\
\hline Internal & $\begin{array}{l}\text { Melakukan pengembangan terhadap } \\
\text { sistem IT untuk mendukung tujuan bisnis } \\
\text { organisasi }\end{array}$ \\
\hline $\begin{array}{l}\text { Pembelajaran dan } \\
\text { pengembangan }\end{array}$ & $\begin{array}{l}\text { Merencanakan pelatihan dan } \\
\text { pengenmbangan terhadap pegawai dan } \\
\text { khususnya pengguna IT untuk } \\
\text { meningkatkan kemampuan individu dalam } \\
\text { penggunaan IT. }\end{array}$ \\
\hline
\end{tabular}




\subsubsection{Enterprise Goals}

Setelah mendapatkan tujuan strategis organisasi, penulis menyelaraskan tujuan strategis dengan tujuan perusahaan dalam COBIT 5. Proses ini akan fokus pada hubungan antara tujuan strategis yang ada dan Enterprise Goals COBIT 5. Tabel 3 dibawah ini merupakan hubungan antara tujuan strategis yang ada dan Enterprise Goals COBIT 5.

Tabel 3. Keterkaitan Tujuan Bisnis dan Enterprise Goals

\begin{tabular}{|c|c|}
\hline Enterprise Goal Cobit 5 & Keterkaitan Tujuan Bisxnis LTC \\
\hline Stakeholder value of business investment & Tidak terkait \\
\hline $\begin{array}{l}\text { Portofolio of competitive products and } \\
\text { services }\end{array}$ & Tidak terkait \\
\hline $\begin{array}{l}\text { Managed business risks (Safeguarding } \\
\text { assets) }\end{array}$ & Tidak terkait \\
\hline $\begin{array}{l}\text { Compliance with external laws and } \\
\text { regulations }\end{array}$ & Tidak terkait \\
\hline Financial Transparency & Terkait \\
\hline Customer oriented service culture & Terkait \\
\hline Business service continuity and availability & Terkait \\
\hline $\begin{array}{l}\text { Agile responses to a changing business } \\
\text { environment }\end{array}$ & Tidak terkait \\
\hline Information based strategic decision making & Terkait \\
\hline Optimisation of service delivery costs & Terkait \\
\hline $\begin{array}{l}\text { Optimisation of business process } \\
\text { functionality }\end{array}$ & Tidak terkait \\
\hline Optimisation of business process costs & Tidak terkait \\
\hline Managed business change programmes & Tidak terkait \\
\hline Operational and staff productivity & Terkait \\
\hline Compliance with internal policies & Tidak terkait \\
\hline Skilled and motivated people & Terkait \\
\hline Product and business innovation culture & Tidak terkait \\
\hline
\end{tabular}

\subsubsection{IT-Related Goals}

Setelah memetakan hubungan antara tujuan bisnis dan tujuan perusahaan, penulis akan menemukan tujuan terkait TI mana yang dapat digunakan. Berikut tabel 4 adalah hasil ITRelated Goals yang didapat

Tabel 4. IT-Related Goals

\begin{tabular}{|l|l|}
\hline \multicolumn{1}{|c|}{ Enterprise Goals } & \multicolumn{1}{c|}{ IT-Related Goals } \\
\hline Financial Transparency & 6 \\
\hline Customer oriented service culture & 1,7 \\
\hline $\begin{array}{l}\text { Business service continuity and } \\
\text { availability }\end{array}$ & $4,10,14$ \\
\hline $\begin{array}{l}\text { Information based strategic } \\
\text { decision making }\end{array}$ & 1,14 \\
\hline $\begin{array}{l}\text { Optimisation of service delivery } \\
\text { costs }\end{array}$ & $4,6,11$ \\
\hline
\end{tabular}




\begin{tabular}{|l|l|}
\hline Operational and staff productivity & 8,16 \\
\hline Skilled and motivated people & 16 \\
\hline
\end{tabular}

\subsubsection{Cobit 5 Process}

Hasil pemetaan IT-Related Goals diatas dapat disupport dalam proses cobit 5 sehingga pemilihan proses dapat disesuaikan dengan tujuan strategis bisnis yang ada. Pada tahap selanjutnya setelah proses pemetaan target terkait TI, beberapa subdomain telah dipilih. ITRelated Goals dan Cobit 5 proses yang terpilih tertera pada tabel 5 dibawah ini.

Tabel 5. IT-Related Goals dan Cobit 5 Proses

\begin{tabular}{|l|l|}
\hline $\begin{array}{c}\text { IT-Related } \\
\text { Goals }\end{array}$ & \multicolumn{1}{c|}{ Cobit 5 Proses } \\
\hline IT-RG 1 & $\begin{array}{l}\text { EDM01,EDM02,APO01,APO02,APO03,APO05,APO07,APO08, } \\
\text { BAI01,BAI02 }\end{array}$ \\
\hline IT-RG 4 & $\begin{array}{l}\text { EDM03,APO10,APO12,APO13,BAI01,BAI06,DSS01,DSS01,DS } \\
\text { S03,DSS04,DSS05,DSS06,MEA01,MEA02,MEA03 }\end{array}$ \\
\hline IT-RG 6 & EDM02,EDM03,EDM05,APO06,APO12,APO13,BAI09 \\
\hline IT-RG 7 & $\begin{array}{l}\text { EDM01,EDM02,EDM05,APO02,APO08,APO09,APO10,APO11, } \\
\text { BAI02,BAI03,BAI04,BAI06,DSS01,DSS02,DSS03,DSS04,DSS0 } \\
\text { 6,MEA01 }\end{array}$ \\
\hline IT-RG 8 & APO04,BAI05,BAI07 \\
\hline IT-RG 10 & EDM03,APO12,APO13,BAI06,DSS05 \\
\hline IT-RG 11 & $\begin{array}{l}\text { EDM04,APO01,APO03,APO04,APO07,BAI04,BAI09,BAI10,DS } \\
\text { S01,DSS03,MEA01 }\end{array}$ \\
\hline IT-RG 14 & APO09,APO13,BAI04,BAI10,DSS03,DSS04 \\
\hline IT-RG 16 & EDM04,APO01,APO07 \\
\hline
\end{tabular}

\subsubsection{Proses Sub Domain}

Setelah mendapatkan tujuan terkait IT dan memahami subdomain/proses yang ada, penulis berkonsentrasi dan memilih domain DSS (Delivery, Service dan Support). Domain DSS merupakan domain yang sesuai ketika layanan perlu dikirimkan, permintaan terpenuhi, dan keberlangsungan tata kelola TI didukung, karena konten tersebut termasuk dalam domain DSS.

Tabel 6. Proses Sub Domain

\begin{tabular}{|l|l|}
\hline Proses Sub Domain & \multicolumn{1}{|c|}{ Practice } \\
\hline DSS1 & Mengelola operasi \\
\hline DSS2 & Mengelola permintaan layanan dan insiden \\
\hline DSS3 & Mengelola masalah \\
\hline DSS4 & Mengelola keberlanjutan \\
\hline DSS5 & Mengelola keamanan layanan \\
\hline DSS6 & Mengelola kontrol proses bisnis \\
\hline
\end{tabular}




\subsubsection{Data Temuan}

Dari subdomain diatas maka penulis membuat beberapa pengumpulan data dengan cara observasi,kuisioner dan wawancara yang didasarkan pada proses sub domain tersebut. Berikut data yang didapatkan mengenai beberapa temuan yang ada di LTC.

Tabel 6. Data Temuan

\begin{tabular}{|c|c|}
\hline Sub Domain - Practice & Data Temuan \\
\hline DSS1 - Mengelola operasi & $\begin{array}{ll}\text { - LTC tidak melakukan } \\
\text { monitoring(pemantauan secara berkala) } \\
\text { terhadap sistem maupun perangkat keras } \\
\text { - Terdapat SOP untuk mendukung aktivitas } \\
\text { layanan } \\
\text { - Memastikan standar keamanan yang } \\
\text { digunakan sesuai dengan kebijakan UKSW } \\
\text { - Sudah melakukan monitoring tetapi belum } \\
\text { menetapkan metode yang benar untuk } \\
\text { infrastruktur TI }\end{array}$ \\
\hline $\begin{array}{l}\text { DSS2 - Mengelola } \\
\text { permintaan layanan dan } \\
\text { insiden }\end{array}$ & $\begin{array}{l}\text { - LTC mempunyai SOP terhadap } \\
\text { permintaan pelayanannya } \\
\text { - LTC tidak memiliki SOP dalam hal perawatan } \\
\text { dan penggunaan sistem dan perangkat keras }\end{array}$ \\
\hline DSS3 - Mengelola masalah & $\begin{array}{l}\text { - LTC belum sepenuhnya } \\
\text { mendokumentasikan atau menyimpan data } \\
\text { untuk setiap permasalahan atau kendala } \\
\text { yang ada } \\
\text { - Membuat laporan tentang kemajuan } \\
\text { penanganan masalah tetapi tidak rutin } \\
\text { Dilakukan }\end{array}$ \\
\hline $\begin{array}{l}\text { DSS4 - Mengelola } \\
\text { keberlanjutan }\end{array}$ & $\begin{array}{l}\text { - LTC tidak melakukan pengecekan sistem } \\
\text { atau perangkat keras secara berkala } \\
\text { - LTC melakukan pengecekan jika saat terjadi } \\
\text { kendala yang tiba-tiba muncul } \\
\text { - LTC kekurangan tenaga kerja dalam bidang } \\
\text { IT } \\
\text { - LTC tidak mempunyai pelatihan khusus IT } \\
\text { pada setiap karyawan }\end{array}$ \\
\hline $\begin{array}{l}\text { DSS5 - Mengelola } \\
\text { keamanan layanan }\end{array}$ & $\begin{array}{l}\text { Dalam menjaga keamanan computer dari } \\
\text { virus LTC menggunakan antivirus Eset } \\
\text { Security } \\
\text { - LTC telah memastikan kemanan jaringan } \\
\text { dan kemanan system agar dapat memenuhi } \\
\text { kebutuhan bisnis }\end{array}$ \\
\hline
\end{tabular}




\begin{tabular}{|l|l|}
\hline $\begin{array}{l}\text { DSS6 - Mengelola kontrol } \\
\text { proses bisnis }\end{array}$ & $\begin{array}{l}\text { Konsistensi aktivitas pengendalian dan } \\
\text { tujuan dalam proses bisnis LTC mengacu } \\
\text { pada kebijakan UKSW }\end{array}$ \\
& $\begin{array}{l}\text { Tidak rutin melakukan pengawasan terhadap } \\
\text { inisiden karena tenaga kerja kurang } \\
\text { memadai di bidang IT }\end{array}$ \\
& $\begin{array}{l}\text { Tidak ada catatan sistem informasi yang } \\
\text { digunakan untuk menentukan riwayat dan } \\
\text { akuntabilitas informasi kegiatan }\end{array}$ \\
\hline
\end{tabular}

Dari proses sub domain diatas diambil 6 proses 37 proses yang ada pada Cobit 5 untuk dilakukan assesment nilai capability level pada masing-masing proses. Langkah selanjutnya adalah mencari nilai tingkat kapabilitas proses dari proses Cobit 5 yang dipilih. Korespondensi antara evaluasi dan nilai jatuh tempo dihitung secara eksponensial menggunakan rumus berikut. Berikut adalah proses perhitungannya:

$$
\begin{aligned}
& \text { Indeks Kematangan Atribut }=\frac{\Sigma(\text { Jawaban Kuisioner })}{\Sigma(\text { Domain Proses })}(1) \\
& \text { Indeks Maturity }=\frac{\% \text { ketercpaian } x \text { Index Kuisioner })}{W \text { Work Product }}(2) \\
& \text { Maturity Level }=\frac{\Sigma(\text { Maturity Index Domain })}{\Sigma(\text { Domain Proses })}(3)
\end{aligned}
$$

\subsubsection{Tingkat Kematangan}

Setelah dilakukan identifikasi tujuan strategis organisasi dan penyebaran kuisioner kepada karyawan yang ada di LTC UKSW. Maka didapatkan hasil pengolahan data sebagai berikut :

Tabel 7. Tingkat Kematangan sub domain DSS di LTC

\begin{tabular}{|l|l|l|l|}
\hline $\begin{array}{l}\text { Sub Domain } \\
\text { DSS }\end{array}$ & AktiVitas & $\begin{array}{l}\text { Nilai } \\
\text { Kematangan }\end{array}$ & $\begin{array}{l}\text { Process } \\
\text { Assesment Result }\end{array}$ \\
\hline DSS 1 & Mengelola operasi & 1,8 & Level 1 \\
\hline DSS 2 & $\begin{array}{l}\text { Mengelola } \\
\text { permintaan layanan } \\
\text { dan insiden }\end{array}$ & 1,22 & Level 1 \\
\hline DSS 3 & Mengelola masalah & 1.64 & Level 1 \\
\hline DSS 4 & $\begin{array}{l}\text { Mengelola } \\
\text { keberlanjutan }\end{array}$ & 1 & Level 1 \\
\hline DSS 5 & $\begin{array}{l}\text { Mengelola keamanan } \\
\text { layanan }\end{array}$ & 1 & Level 1 \\
\hline DSS 6 & $\begin{array}{l}\text { Mengelola kontrol } \\
\text { proses bisnis }\end{array}$ & 1,39 & Level 1 \\
\hline \multicolumn{2}{|l}{$\begin{array}{l}\text { Maturity Level Domain } \\
\text { DSS }\end{array}$} & $\mathbf{1 , 3 4}$ \\
\hline
\end{tabular}

Total tingkat kematangan dari penilaian terhadap pada domain DSS yaitu 1,34, menunjukkan berada pada posisi Level 1 (Performed Process). Berarti proses sedang dijalankan, namun harus diikuti dan dimaksimalkan agar tujuan dapat tercapai. Dan berikut adalah pemaparan hasil tingkat kematangan untuk setiap sub Domain DSS. 


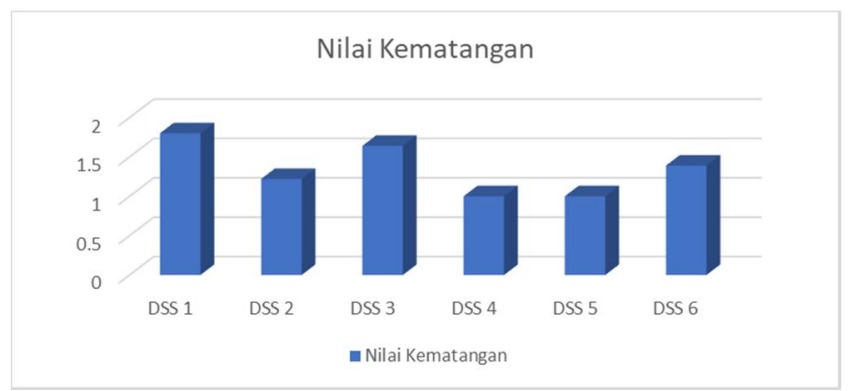

Gambar 5. Tingkat Kematangan

Berdasarkan tingkat kematangan yang diperoleh dari hasil penghitungan kuisioner, jika dibandingkan dengan tingkat yang diharapkan yang berada pada level 5 (Optimized Process), ternyata masih terdapat kesenjangan. Tahap selanjutnya adalah, melakukan analisis terhadap masing-masing sub domain agar dapat memberikan kemudahan bagi pengelola. Proses ini dilkukan dengan cara nilai tingkat kematangan saat ini dikurangi dengan tingkat kematangan yang diharapakan. Analisis dapat dilihat pada tabel dibawah ini

Tabel 8. Tingkat Kesenjangan

\begin{tabular}{|l|l|l|l|}
\hline \multirow{2}{*}{$\begin{array}{c}\text { Sub } \\
\text { Domain }\end{array}$} & \multicolumn{3}{|c|}{ Tingkat Kematangan } \\
\cline { 2 - 4 } & Saat Ini & Diharapkan & $\begin{array}{c}\text { Kesenjangan = } \\
\text { (Diharapkan-Saat ini) }\end{array}$ \\
\hline DSS 1 & 1,8 & 5 & 3,2 \\
\hline DSS 2 & 1,22 & 5 & 3,78 \\
\hline DSS 3 & 1.64 & 5 & 3,36 \\
\hline DSS 4 & 1 & 5 & 4 \\
\hline DSS 5 & 1 & 5 & 4 \\
\hline DSS 6 & 1,39 & 5 & 3,61 \\
\hline
\end{tabular}

Berdasarkan hasil analisis tingkat kesenjangan diatas makan didapat hasil pada sub domain DSS 1 mempunyai nilai 3,1, DSS 2 mempunyai nilai 3,78, DSS 3 mempunyai nilai 3,36, DSS 4 mempunyai nilai 4, DSS 5 mempunyai nilai 4, dan DSS 6 mempunyai nilai 3,61. Jadi total nilai kesenjangan yang ada adalah 3,65 dari tingkat yang diharapkan. Adapun grafik tingkat kematangan untuk semua sub domain DSS yang ada pada LTC UKSW adalah sebagai berikut.

\subsection{Rekomendasi}

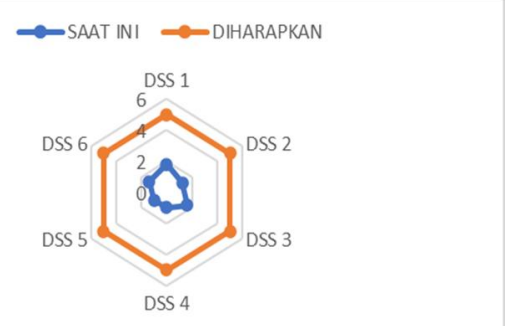

Gambar 2. Analisa Kesenjangan (GAP)

Berdasarkan hasil pengolahan data dan temuan dari proses wawancara dan kuisioner, maka didapatkan rekomendasi untuk perbaikan TI untuk masa mendatang. Berikut adalah hasil rekomendasi yang diperoleh. 
Tabel 9. Rekomendasi

\begin{tabular}{|c|c|}
\hline Proses & Rekomendasi \\
\hline DSS 1 & $\begin{array}{l}\text { - LTC harus melaukan pelaihan kerja terutama pada bidang IT } \\
\text { agar setiap karyawan dapat menggunakan IT dengan baik } \\
\text { - LTC harus melakukan pengecekan fasilitas TI secara rutin tanpa } \\
\text { menunggu adanya gangguan/masalah terlebih dahulu }\end{array}$ \\
\hline DSS 2 & $\begin{array}{l}\text { - Melakukan perbaikan dalamfasilitas TI pada hardware maupun } \\
\text { software } \\
\text { - Tentukan metode untuk mendukung permintaan layanan yang } \\
\text { terkait dengan peristiwa bermasalah di TI agar lebih efisien }\end{array}$ \\
\hline DSS 3 & $\begin{array}{l}\text { - Dokumentasi harus dilakukan secara rutin sehingga dapat } \\
\text { ditemukan peningkatan solusi masalah }\end{array}$ \\
\hline DSS 4 & $\begin{array}{l}\text { - LTC harus menambah tenaga kerja dalam bidang IT agar } \\
\text { penggunaan IT yang ada dapat dilakukan dengan efektif } \\
\text { - Rapat kordinasi secara rutin agar dapat melakukan evaluasi dan } \\
\text { koreksi terhadap masalah yang ada sehingga dapat meminimalisir } \\
\text { resiko masalah di masa mendatang }\end{array}$ \\
\hline DSS 5 & $\begin{array}{l}\text { - Pembatasan akses pengguna ke aset TI perlu ditingkatkan } \\
\text { - LTC harus memberikan hak akses yang berbeda kepada setiap } \\
\text { pengguna untuk mengantisipasi kemungkinan kecurangan atau } \\
\text { insiden sehingga pengguna dapat bertanggung jawab atas pekerjaan } \\
\text { dan komputer mereka. } \\
\text { - Memberikan peringatan kepada setiap user akan kesadaran } \\
\text { kemanan system yang dimiliki }\end{array}$ \\
\hline DSS 6 & $\begin{array}{l}\text { - Melaksanakan review, mencatat dan evaluasi insiden atau masalah } \\
\text { dalam kelangsungan proses bisnis }\end{array}$ \\
\hline
\end{tabular}

\section{KESIMPULAN}

COBIT 5 merupakan salah satu alat ukur yang dapat digunakan untuk mengevaluasi kinerja layanan TI di LTC UKSW. Melalui evaluasi tersebut terlihat kondisi TI LTC UKSW saat ini. Hasil pengukuran tingkat kapabilitas dengan menggunakan Process Assessment Model (PAM), bahwa proses yang diukur yaitu pada DSS 1, DSS 2, DSS 3, DSS 4 dan DSS 5, DSS 6 berada pada level 1 (Performed Process) menunjukkan bahwa proses telah dilaksanakan pada tingkat ini dan tujuan proses telah tercapai. Dalam hal ini LTC UKSW rata-rata berada pada level 1 LTC UKSW menyadari pentingnya pengelolaan TI dalam proses bisnis yang dibuktikan dengan adanya pemeliharaan TI dan pengelolaan masalah yang terjadi. Setiap proses subdomain diberikan rekomendasi perbaikan yang nantinya bisa mempengaruhi tingkat kematangan saat ini untuk menuju tingkat perbaikan dan sampai pada kematangan yang ingin dicapai berikut untuk meningkatkan proses kinerja instansi kearah yang lebih baik. Pemberian rekomendasi adalah berdasarkan pada level COBIT 5 dan juga mengacu pada fungsi dari Governance yakni memastikan bahwa Proses TI yang dimiliki instansi benar - benar memberikan nilai tambah bagi bisnis, dan Management yang menjalankannya. 


\section{SARAN}

Setelah peneliti menyelesaikan Analisis Sistem Informasi Berbasis Cobit 5 di LTC UKSW, untuk peneliti di kemudian hari dapat melakukan penelitian dengan cakupan lebih luas sehingga temuan-temuan yang ada dapat digunakan oleh pemangku kebijakan untuk menyusun dokumentasi terkait dengan tata kelola organisasi.

\section{UCAPAN TERIMA KASIH}

Penulis mengucapakan banyak terima kasih kepada Tuhan Yang Maha Esa atas penyertaan dan kekuatan yang telah diberikan sehingga penulis dapat menyelesaikan jurnal ini. Penulis juga mengucapkan terima kasih kepada keluarga, dosen pembinbing, mentor di kantor, narasumber yang bersedia menyediakan waktunya untuk melakukan wawancara dan temanteman terdekat. Sekali lagi terima kasih yang sebesar-besarnya kepada semua yang terlibat dalam penulisan yang selalu memberikan dukungan kepada penulis.

\section{DAFTAR PUSTAKA}

[1] De Haes, S. \& Van Grembergen, W. 2004, IT Governance Structures, Processes, and relational Mechanism: Acheiving IT/Business Alignment in A Major Belgian Financial Group.

[2] Omari, L. A., Barnes, P., \& Pitman, G. 2012, Optimising COBIT 5 for IT Governance: Examples from the Public Sector. International Conference on Applied and Theoretical Information Systems Research (pp. 1-13). Taipei, Taiwan: Queensland University of Technology.

[3] Carlos, J., Carlos, G., \& Isaac, L. 2014, Implementing Good Governance Principles for The Public Sector in Information Technology Governance Frameworks. Open Journal of Accounting , 3 (1), 9-27.

[4] Waluyan, G., \& Manuputty, A. 2016, Evaluasi Kinerja Tata Kelola TI Terhadap Penerapan Sistem Informasi Star Click Framework COBIT 5 (Studi Kasus: PT. Telekomunikasi Indonesia, TBK Semarang). Jurnal Teknologi dan Sistem Informasi, 2, 157. https://doi.org/10.25077/TEKNOSI.v2i3.2016.157-166.

[5] Belegur, J. A. I., Rudianto, C., \& Sitokdana, M. 2018, Evaluasi Tata Kelola Teknologi Informasi Dinas Pariwisata dan Kebudayaan Kota Ambon Menggunakan Framework Cobit 5.0 pada Domain Monitor, Evaluate and Asses (MEA). Aiti, 15(2), 107-114. https://doi.org/10.24246/aiti.v15i2.107-114.

[6] Wijaya, A. F., \& Andani, A. T. 2017, Evaluasi Kinerja Sistem informasi E-Filing Menggunakan COBIT 5 pada Kantor Pelayanan Pajak Pratama Kota Salatiga, Jurnal Terapan Teknologi Informasi, 1(1), 61-70. https://doi.org/10.1186/s13104 017-3108-5.

[7] Ambarwati, A., \& Rusady, R. 2017, Analisis Implementasi Teknologi Informasi pada Domain Deliver and Support di PT. RDPI, Jurnal INFORM, 2(2). https://doi.org/10.25139/ojsinf.v2i2.315. 
[8] Kristanto, T., Lestari, L A., \& Sulistyowati. 2016, Analisis Tingkat Kematangan EGovermnment Menggunakan Framework COBIT 5. Studi Kasus: Dinas Perdagangan dan Perindustrian Kota Surabaya), Seminar Nasional Sistem Informasi. http://is.its.ac.id/pubs/oajis/index.php/file/downloa d_file/1664.

[9] Arens, Alvin. A., dan James K. Loebbecke. 2003, Auditing, Pendekatan Terpadu, Terjemahan Amir Abadi Jusuf, Salemba Empat, Jakarta.

[10] ISACA. 2012, Cobit 5; A Business Framework for The Governance and Management of Enterprise IT.

[11] Robert S. Kaplan and David P. Norton. 1996, The Balanced Scorecard: Translating Strategy Into Action, Harvard Business School Press 